\title{
Applications of Amine-functionalized Mesoporous Silica in Fine Chemical Synthesis
}

\author{
Soofin Cheng $\cdot$ Xueguang Wang $\cdot$ Shih-Yuan Chen
}

Published online: 10 April 2009

(C) Springer Science+Business Media, LLC 2009

\begin{abstract}
SBA-15 silica containing homogeneously distributed amine-functional groups and of fiber or platelet morphology was prepared through a modified co-condensation method using P123 copolymer as template under acidic condition. Synthetic factors which led to wellordered mesoporous materials with high loadings of various amine groups were discussed. The resultant mesoporous materials were efficient base catalysts in Knoevenagel and Claisen-Schmidt addition reactions. The activities over SBA-15 materials with different aminofunctional groups are compared. Moreover, the advantage of ordered large mesopores of SBA-15 in catalyzing liquid phase reactions was demonstrated, and the reaction rate could be further increased when SBA-15 was with platelet morphology and short mesochannels.
\end{abstract}

Keywords Mesoporous silica - Amine - Functionalized · One-pot synthesis $\cdot$ Fine chemicals $\cdot$ Base-catalyst

\section{Introduction}

Since the discovery of mesoporous silicates M41S [1, 2], the surfactant-templated mesoporous materials of uniformly

Dedicated to the 50th Anniversary of Catalysis Society of Japan.

S. Cheng $(\bowtie) \cdot X$. Wang $\cdot$ S.-Y. Chen

Department of Chemistry, National Taiwan University,

No. 1, Sec. 4, Roosevelt Road, Taipei 10617, Taiwan

e-mail: chem1031@ntu.edu.tw

X. Wang

Department of Materials and Engineering, School of Materials

Science and Engineering, Shanghai University,

Shanghai 200072, China arranged pores with tuneable pore diameter in $1.5-10 \mathrm{~nm}$ and very high surface areas (ca. $1000 \mathrm{~m}^{2} / \mathrm{g}$ ) are technologically promising for applications in catalysis [3, 4], sensors [5], electronic devices [6], and biomedicines [7]. Many researches have focused on the preparation of organic functionalized materials to expand the applications by either direct incorporation of organic groups through co-condensation or grafting the organic groups onto the surface of the calcined mesoporous silica [8-15]. The co-condensation method is often preferred to the post-synthesis pathway because it minimizes processing steps and provides a more uniform distribution of the organic functionalities [16]. In addition, one-pot co-condensation synthesis often provides a higher loading of the organic functionalities without closing the pore mouths [17].

Amino-functionalized mesoporous silica have been found to be useful for base-catalyzed reactions [17] or further post-synthesis functionalization [18, 19]. However, the preparation of the large mesoporous silica by co-condensation of tetraethylorthosilicate (TEOS) and aminosilane using triblock copolymer Pluronic P123 (EO20PO70EO20) as pore-directing agent under acidic conditions only results in disordered materials [20, 21]. It was attributed to that the protonated amine groups not only interfere the self-assembly of the pore-directing agent and the silica precursor but also interact strongly with the ethoxy groups of TEOS through hydrogen bond so that the hydrolysis and condensation of ethoxysilane are inhibited [21]. In the past several years, our laboratory has synthesized with success well ordered SBA-15 mesoporous silica containing high loadings of amine groups, including primary, secondary amines and diamine. This article summarizes some key factors in the synthesis conditions which would lead to well-ordered mesoporous materials with high loadings of amine-functional groups. Moreover, the 
catalytic applications in fine chemical synthesis are demonstrated, and the activities over functionalized mesoporous materials with different amine-groups are compared. At last, the importance of ordered porous structures is demonstrated. Furthermore, platelet SBA-15 of very short mesochannels is superior to the conventional SBA-15 in facilitating molecular diffusion and less possibility of pore blockage when used in the reactions of bulky molecules.

\section{Experimental Section}

In the typical synthesis of amino-functionalized SBA-15, $4 \mathrm{~g}$ of Pluronic 123 and $11 \mathrm{~g}$ of $\mathrm{NaCl}(1.5 \mathrm{M})$ were dissolved in $125 \mathrm{~g}$ of $2.0 \mathrm{M} \mathrm{HCl}$ solution with stirring at room temperature. After adding TEOS, the resultant solution was hydrolyzed at $40{ }^{\circ} \mathrm{C}$ for 1 or $2 \mathrm{~h}$ before adding the organic silane slowly. The molar composition of the mixture was $(1-\mathrm{x})$ TEOS: $\mathrm{x}$ organic silane: $6.1 \mathrm{HCl}: 4.6 \mathrm{NaCl}: 0.017$ $\mathrm{P} 123: 165 \mathrm{H}_{2} \mathrm{O}$, where $\mathrm{x}$ varied from 0 to 0.20 . The resulting mixture was stirred at $40{ }^{\circ} \mathrm{C}$ for $20 \mathrm{~h}$ and then transferred into a polypropylene bottle and aged at $90{ }^{\circ} \mathrm{C}$ under static condition for $24 \mathrm{~h}$. The solid product was recovered by filtration and dried at room temperature overnight. The template was removed from the as-made material by refluxing in $95 \%$ ethanol for $24 \mathrm{~h}$. Finally, the material was filtered, washed several times with water and ethanol and dried at $50{ }^{\circ} \mathrm{C}$.

The liquid phase catalytic reactions were carried out under $\mathrm{N}_{2}$ in a sealed flask immersed in a thermostat bath with a magnetic stirrer. Before the catalytic reaction, the functionalized SBA-15 materials were treated with $0.2 \mathrm{M}$ methanol solution of tetramethylammonium hydroxide (TMAOH) for $30 \mathrm{~min}$, followed by washing with large amount of water and ethanol, to remove the residue $\mathrm{Cl}^{-}$ions and to neutralize the protonated amine groups. In the catalysis experiment, the reactants (with or without the solvent) were mixed in the flask and heated to the set reaction temperature before $0.15 \mathrm{~g}$ of the dried catalyst was rapidly added. The liquid products were separated from the reaction mixture at appropriate reaction intervals with a filtering syringe and diluted with chlorobenzene for analysis. The products were identified by GC-MS (HP5971 mass spectrometer) and analyzed using a Chrompak CP 9000 GC equipped with an FID detector.

\section{Results and Discussion}

\subsection{Amino-functionalized SBA-15}

Aminopropyl-functionalized SBA-15 materials (denoted as SBA- $\mathrm{NH}_{2}$ ) were prepared by an improved one-pot method

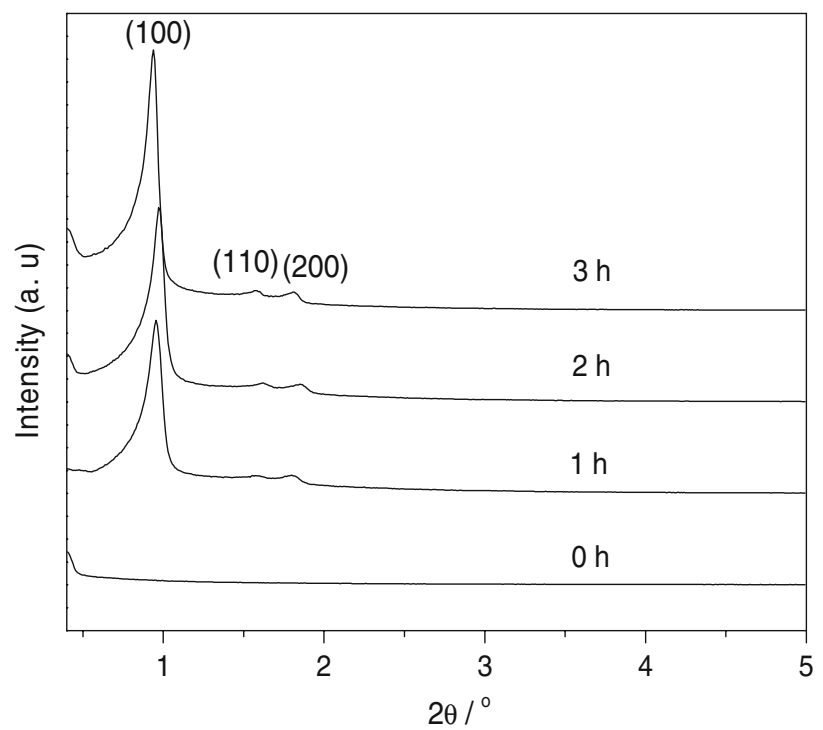

Fig. 1 XRD patterns of the extracted $10 \% \mathrm{SBA}^{-\mathrm{NH}_{2}}$ with different TEOS pre-hydrolysis periods [23]

[22, 23]. The pre-hydrolysis of TEOS prior to the addition of amine-containing silanes was found one of the key steps in preparing amino-functionalized SBA-15 of ordered structure using P123 as pore-directing agent under acidic condition. Figure 1 shows the XRD patterns of the ethanol extracted SBA-15 containing 10\% aminopropyl groups (designated as $10 \% \mathrm{SBA}-\mathrm{NH}_{2}$ ) prepared with different prehydrolysis periods [23]. In contrast to the $\mathrm{X}$-ray amorphous sample obtained without pre-hydrolysis, the intense (100) reflection and weaker (110) and (200) reflections of 2D-hexagonal phase appear when the TEOS pre-hydrolysis time reaches to $1 \mathrm{~h}$. The intensity of the diffraction peaks increases with the pre-hydrolysis time, indicating more ordered mesoporous structure was formed. $\mathrm{N}_{2}$ physisorption isotherms showed that the $\mathrm{SBA}-\mathrm{NH}_{2}$ materials prepared with TEOS pre-hydrolysis for 1-6 $\mathrm{h}$ all exhibited type IV isotherms with $\mathrm{H} 1$ hysteresis loops. As to the sample prepared without TEOS pre-hydrolysis, no apparent hysteresis loop was observed. It is shown in Table 1 that $10 \% \mathrm{SBA}^{-\mathrm{NH}_{2}}$ prepared with TEOS pre-hydrolysis for 1-3 h display much higher surface areas and larger pore volumes than that without pre-hydrolysis. However, if the pre-hydrolysis period was lengthened to $4 \mathrm{~h}$ or longer, the surface area, pore volume and pore diameter of the resultant $\mathrm{SBA}-\mathrm{NH}_{2}$ decreased. Elemental analyses indicated that the amount of aminopropyl groups incorporated in the silica framework was independent of the pre-hydrolysis period in the range of 1-3 $\mathrm{h}$, while the nitrogen content increased slightly with longer pre-hydrolysis period. Based on these results, pre-hydrolysis of TEOS for longer than $3 \mathrm{~h}$ is probably not a suitable condition to prepare aminofunctionalized SBA-15. In such a condition, the surfactant- 
Table 1 Physical properties and amino groups contents of the extracted $10 \%$ SBA- $\mathrm{NH}_{2}$ with different pre-hydrolysis periods [23]

\begin{tabular}{llllll}
\hline $\begin{array}{l}\text { Pre-hydrolysis } \\
\text { period }(\mathrm{h})\end{array}$ & $\begin{array}{l}\mathrm{D}_{100} \\
\text { spacing }(\mathrm{nm})\end{array}$ & $\begin{array}{l}\text { Pore } \\
\text { diameter }(\mathrm{nm})\end{array}$ & $\begin{array}{l}\mathrm{S}_{\mathrm{BET}} \\
\left(\mathrm{m}^{2} / \mathrm{g}\right)\end{array}$ & $\begin{array}{l}\text { Pore volume } \\
\left(\mathrm{cm}^{3} / \mathrm{g}\right)\end{array}$ & $\begin{array}{l}\text { N content by EA } \\
(\mathrm{mmol} / \mathrm{g})\end{array}$ \\
\hline 0 & - & - & 447 & 0.26 & 1.28 \\
1 & 9.2 & 6.7 & 664 & 0.85 & 1.21 \\
2 & 9.1 & 6.5 & 573 & 0.75 & 1.23 \\
3 & 9.4 & 6.9 & 593 & 0.79 & 1.23 \\
4 & 8.9 & 6.3 & 412 & 0.60 & 1.33 \\
6 & 8.9 & 6.3 & 459 & 0.63 & 1.34 \\
\hline
\end{tabular}

silica assembly formed by TEOS condensation may be too compact to allow aminosilane to diffuse freely into the soft area and condensation. Instead, aminosilane would concentrate near the pore mouths and partially block the pores.

In general, The BJH pore diameter, BET surface area, and pore volume of the extracted functionalized SBA-15 decrease but the wall thickness increases with the increase in amine content. These results are attributed to the occupation of the organic molecules on the surface of the pores as well as the perturbation of amine groups during the silicate condensation process.

We have also extended the one-pot synthesis technique to prepare SBA-15 materials functionalized with secondary amine and diamine groups using 3-(methylamino)propyl)trimethoxysilane (MAPTMS) and methylaminopropyl [3-(2-Aminoethyl aminopropyl)] trimethoxysilane (ATMS), respectively, as the organic silanes [24, 25]. The three different amine-functional groups examined in this study are displayed in Scheme 1. The prehydrolysis period of TEOS for secondary amine and diamine groups needed to be around $2 \mathrm{~h}$ in order to obtain functionalized SBA-15 materials with optimal pore ordering and surface areas.

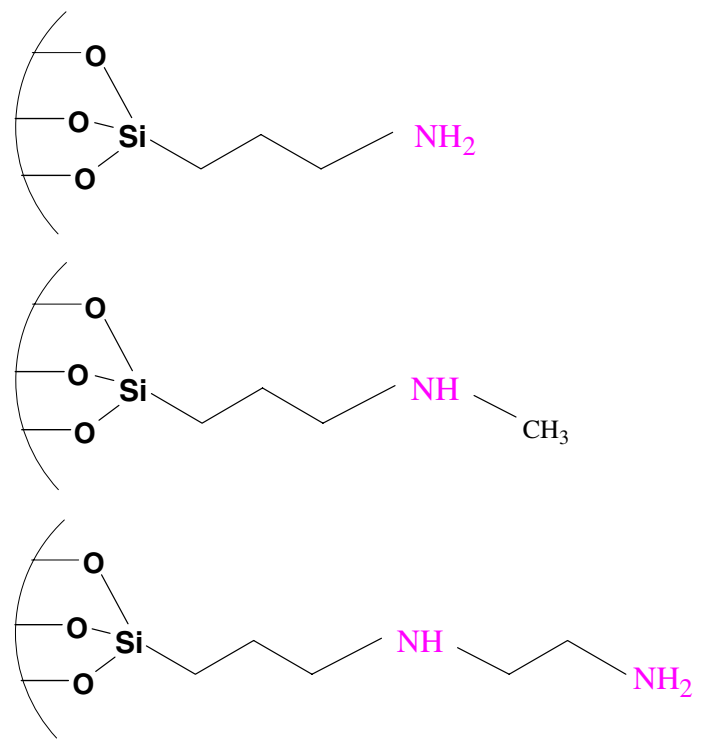

Scheme 1 SBA-15 with various amine-functional groups prepared by one-pot method
Moreover, the addition of $\mathrm{NaCl}$ to the synthesis mixture greatly improve the stability of the silica framework, especially when functionalized with high loadings (15-20 mol\%) of methylaminopropyl and diamine groups. Table 2 shows the textural properties of extracted methylaminopropyl functionalized SBA-15 materials synthesized with various concentrations of MAPTMS and $\mathrm{NaCl}$ in the initial mixtures. The materials synthesized with 15 and 20 mol\% MAPTMS lost the crystallographic ordering after ethanol-extraction. However, the addition of $\mathrm{NaCl}$ to the synthesis mixture greatly improve the stability of the functionalized silica framework. Moreover, the d-spacings of the (100) diffraction peak increased when $\mathrm{NaCl}$ was present in the synthesis solution. In combination of TEOS prehydrolysis and addition of $\mathrm{NaCl}$ salt, the modified SBA-15 materials with the content of methylaminopropyl groups up to $2.37 \mathrm{mmol} / \mathrm{g}$ and diamine groups up to $1.54 \mathrm{mmol} \mathrm{g}^{-1}$ still possessed well-ordered mesoporous structure and had specific areas larger than $200 \mathrm{~m}^{2} \mathrm{~g}^{-1}$ and pore volume larger than $0.29 \mathrm{~cm}^{3} / \mathrm{g}$. Similar salt effect was also observed in the synthesis of periodic mesoporous organosilicas [10, 26]. It has been proposed that salt may influence the hydrolysis and condensation kinetics of the silica precursors [27]. Moreover, the salting-out effect of the inorganic electrolyte may stabilize the micelle structure and facilitate the formation of well-ordered mesoporous silica.

\subsection{Catalytic Performance}

The amino-functionalized SBA-15 materials were all efficient base catalysts in Knoevenagel reactions of carbonyl compounds with ethyl cyanoacetate, and those functionalized with aminopropyl and methylaminopropyl were active in the aldol condensation and subsequent intramolecular Michael addition of benzaldehyde and $2^{\prime}$-hydroxyacetophenone to flavanone. Table 3 displays the results of the Knoevenagel condensation of aldehyde or ketones with ethyl cyanoacetate over $10 \% \mathrm{SBA}-\mathrm{NH}_{2}$ catalyst at $82{ }^{\circ} \mathrm{C}$. For comparison, some of the reaction results under similar reaction condition reported in the literature using aminopropyl functionalized MCM-41 with similar amine content $\left(1.2 \mathrm{mmol} \mathrm{g}^{-1}\right)$ and a pore diameter of $3.6 \mathrm{~nm}$ are given in 
Table 2 Physicochemical properties of the extracted functionalized materials synthesized with various concentrations of MAPTMS and $\mathrm{NaCl}$ in the initial mixtures [24]

\begin{tabular}{llllll}
\hline Sample & $\begin{array}{l}\mathrm{D}_{100} \\
\text { spacing }(\mathrm{nm})\end{array}$ & $\begin{array}{l}\text { Pore } \\
\text { diameter }\end{array}$ & $\mathrm{S}_{\mathrm{BET}}(\mathrm{mm})$ & $\begin{array}{l}\text { Pore } \\
\text { volume }\left(\mathrm{cm}^{3} / \mathrm{g}\right)\end{array}$ & $\begin{array}{l}\text { Wall } \\
\text { thickness }(\mathrm{nm})\end{array}$ \\
\hline $\mathrm{SBA}^{2} 15$ & 9.3 & 7.8 & 769 & 1.0 & 3.0 \\
$5 \% \mathrm{NHCH}_{3}$ & 8.9 & 6.7 & 602 & 0.71 & 3.6 \\
$10 \% \mathrm{NHCH}_{3}$ & 9.1 & 6.4 & 528 & 0.59 & 4.0 \\
$15 \% \mathrm{NHCH}_{3}$ & 8.2 & 2.9 & 280 & 0.23 & 6.6 \\
$20 \% \mathrm{NHCH}_{3}$ & - & - & 55 & 0.06 & - \\
$15 \% \mathrm{NHCH}_{3}-0.5 \mathrm{NaCl}$ & 9.2 & 5.9 & 303 & 0.35 & 4.7 \\
$15 \% \mathrm{NHCH}_{3}-1.0 \mathrm{NaCl}$ & 9.0 & 6.2 & 349 & 0.47 & 4.3 \\
$15 \% \mathrm{NHCH}_{3}-1.5 \mathrm{NaCl}$ & 9.1 & 6.6 & 384 & 0.50 & 3.8 \\
$20 \% \mathrm{NHCH}_{3}-1.5 \mathrm{NaCl}$ & 9.2 & 6.0 & 200 & 0.29 & 4.6 \\
\hline
\end{tabular}

Table 3 Knoevenagel reaction of carbonyl compounds (10 mmol) with ethyl cyanoacetate $(10 \mathrm{mmol})$ in cyclohexane $(10 \mathrm{~mL})$ over $10 \% \mathrm{SBA}^{-\mathrm{NH}_{2}}(0.15 \mathrm{~g})$ [23]
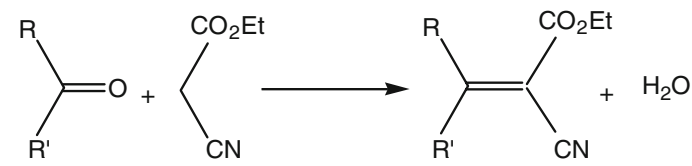

\begin{tabular}{lllll}
\hline Reaction & $\mathrm{R}$ & $\mathrm{R}^{\prime}$ & ${\text { Time }(\mathrm{h})^{\mathrm{b}}}$ & ${\text { Yield }(\%)^{\mathrm{a}, \mathrm{b}}}$ \\
\hline 1 & $\mathrm{C}_{6} \mathrm{H}_{5}$ & $\mathrm{H}$ & $1(36)$ & $>99(94)$ \\
2 & $\mathrm{C}_{4} \mathrm{H}_{9}$ & $\mathrm{Me}$ & 8 & 89.3 \\
3 & $\mathrm{Et}$ & $\mathrm{Et}$ & $8(30)$ & $69.4(89)$ \\
4 & $\mathrm{C}_{3} \mathrm{H}_{7}$ & $\mathrm{Et}$ & 8 & 69.6 \\
5 & $\mathrm{cC}_{5} \mathrm{H}_{10}$ & & $3(12)$ & $>99(70)$ \\
6 & $\mathrm{C}_{6} \mathrm{H}_{5}$ & $\mathrm{Me}$ & 24 & 50.3 \\
\hline
\end{tabular}

The removal of water was not carried out in the reaction procedure a $n$-dodecane as internal standard

b Data in parenthesis are from reference 17, reaction condition: $20 \mathrm{mmol}$ carbonyl compounds, $20 \mathrm{mmol}$ ethyl cyanoacetate, $25 \mathrm{~mL}$ cyclohexane, $82{ }^{\circ} \mathrm{C}$

parenthesis [17]. All the reactions were found to proceed to the olefin products and no intermediate alcohols or other side products were detected. It was noticed in Table 3 that aldehyde and cycloketone gave the highest yield, while aromatic ketone have the lowest yield. That is attributed to the steric hindrance around the carbonyl group in the addition reaction. In comparison to that over MCM-41 of similar amine loading but smaller pore diameter, SBA- $\mathrm{NH}_{2}$ gave higher activities in these reactions, in concerning the product yield and the time period needed in the reaction. These results confirm that the relatively large mesopores of SBA-15 facilitate the diffusion of reactants, products and solvents encountered in the liquid phase reactions, and the reactants access more easily to the catalytic sites on SBA15 than on MCM-41.

The performance of the diamine-functionalized SBA-15 (designated as SBA-ED) was compared with that of aminopropyl-functionalized counterpart in the Knoevenagel reaction of benzaldehyde with ethyl cynoacetate to form $\alpha, \beta$-unsaturated compound in liquid phase [25]. Figure 2 gives the dependency of the yields of $\alpha$, $\beta$-unsaturated compound on the reaction period over various amine-functionalized SBA-15 materials. All the catalysts showed rapid reaction rates in the first $150 \mathrm{~min}$, after this the yields of the product only increased slightly. This might be due to the deactivation of the catalysts by adsorption of formed water and a trace amount of amide product [17]. The product yields increase with the nitrogen content in the catalysts, except the catalyst with the highest diamine loading (20\%SBA-ED), which has very low surface area and pore volume. Since each diamine functional group contains a primary amine and a secondary amine sites but aminopropyl group contains only one amine site, it is expected that aminopropyl-functionalized 10\%SBA$\mathrm{NH}_{2}$ catalyst should have similar amine sites as diaminefunctionalized 5\%SBA-ED catalyst. On the other hand, analysis shows that single amine-functionalized $10 \%$ SBA$\mathrm{NH}_{2}$ has higher surface area, larger pore volume and higher $\mathrm{N}$ content than 5\%SBA-ED. Nevertheless, the catalytic activity of $10 \% \mathrm{SBA}^{-\mathrm{NH}_{2}}$ is lower than the diamine-functionalized 5\%SBA-ED as shown in Fig. 2. The discrepancy is so marked that it is proposed that the two amine sites on the diamine group might have synergistic effect to some extent. The detailed mechanism will need further investigation. The spent $10 \%$ SBA-ED was treated with methanol in a Soxhlet apparatus for $3 \mathrm{~h}$ and then dried at $120^{\circ} \mathrm{C}$ overnight before tested as a catalyst again. The re-used catalyst gave only slightly lower activity than the fresh catalyst ( $85 \%$ vs. $93 \%$ yield after $8 \mathrm{~h}$ ), indicating that most of the active sites could be regenerated by a simple solvent treatment.

We also examined the catalytic activities of aminofunctional SBA-15 in the synthesis of flavanone [28]. Flavonoids are polyphenolic compounds that are widely distributed in plants preserving the health of plants against infections and parasites. They have attracted increasing 


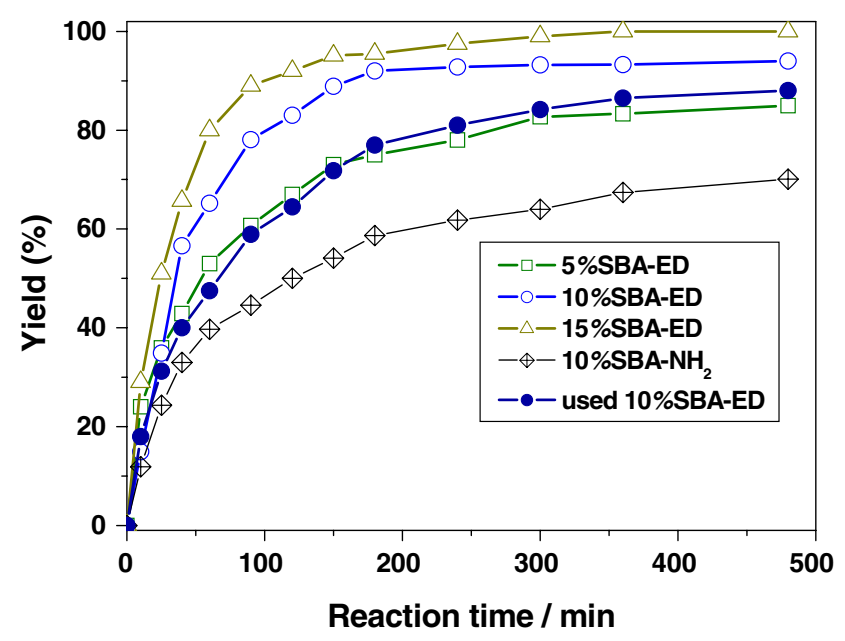

Fig. 2 Knoevenagel reaction of benzaldehyde with ethyl cyanoacetate in cyclohexane over various diamine-functionalized SBA-15 catalysts (SBA-ED) at $35^{\circ} \mathrm{C}$, in comparison to that of $10 \% \mathrm{SBA}-\mathrm{NH}_{2}$ [25]

attention due to numerouspharmacological applications [29-31]. The most common synthesis of the flavonoids is performed via the Claisen-Schmidt condensation and subsequent intramolecular Michael addition between substituted 2'-hydroxyacetopheones $(A)$ and substituted benzaldehydes $(B)$ in basic or acidic media under homogeneous conditions, as shown in Table 4 [32-34]. Our results showed very high catalytic activity and selectivity to flavanone in both organic solutions and solvent-free condition. Especially, the elimination of organic solvents is a frequent goal in green chemistry and the aminopropyl functionalized SBA-15 catalyst showed high activity in solvent free condition. A $84 \%$ conversion of $A$ and $70 \%$ selectivity to flavanone ( $D$ in Table 4 ) was obtained with the $B / A$ molar ratio of 1 . The conversion of $A$ was further increased to $92 \%$ when the $B / A$ molar ratio was increased to 1.5 . No products other than $2^{\prime}$-hydroxychalcone $(C)$ and $D$ were formed in the reaction, and the selectivities of $C$ and $D$ were found to be a result of the thermodynamic equilibrium. When the spent catalyst was re-used after it was washed with ethanol and dried at $120{ }^{\circ} \mathrm{C}$, a slightly lower conversion of $A(81 \%$ vs. $92 \%)$ and similar selectivity to $D$ were observed. The decrease in conversion is probably due to the incomplete removal of absorbed species from the active sites by ethanol. On the other hand, the same reaction using pure siliceous SBA-15 as catalyst gave very low conversion (3\%) of $A$. These results confirm that the catalytic active sites in amino-functionalized SBA-15 are the aminopropyl groups instead of any surface $\mathrm{Si}-\mathrm{O}^{-}$ groups if they were present.

Table 4 Reactions between $2^{\prime}$-hydroxyacetophenone $(10 \mathrm{mmol})$ and benzaldehyde $(15 \mathrm{mmol})$ with various substituting groups in the absence of solvent over SBA-15 functionalized with aminopropyl- $\left(\mathrm{NH}_{2}\right)$ and methylaminopropyl-( $\left.\mathrm{NHCH}_{3}\right)$ at $140{ }^{\circ} \mathrm{C}$ for $8 \mathrm{~h}$<smiles>[R]c1ccc(C2CC(=O)c3cc([R])ccc3OC2c2ccc([R])cc2C#C)c(O)c1</smiles>

\begin{tabular}{lllll}
\hline Catalyst & $\mathrm{R}$ & $\mathrm{R}^{\prime}$ & Conv. of $A(\%)$ & Select. to $D(\%)$ \\
\hline $\mathrm{NH}_{2}$ & $\mathrm{H}$ & $\mathrm{H}$ & 92 & 69 \\
$\mathrm{NH}_{2}$ & $\mathrm{H}$ & $\mathrm{NO}_{2}$ & 66 & 86 \\
$\mathrm{NH}_{2}$ & $\mathrm{H}$ & $\mathrm{Cl}$ & 83 & 73 \\
$\mathrm{NH}_{2}$ & $\mathrm{H}$ & $\mathrm{CH}_{3} \mathrm{O}$ & 87 & 61 \\
$\mathrm{NH}_{2}$ & $\mathrm{CH} \mathrm{O}$ & $\mathrm{H}$ & 89 & 84 \\
$\mathrm{NH}_{2}$ & $\mathrm{Cl}$ & $\mathrm{H}$ & 92 & 75 \\
$\mathrm{NH}_{2}$ & $\mathrm{CH} \mathrm{O}$ & $\mathrm{CH} \mathrm{O}$ & 82 \\
$\mathrm{NHCH}_{3}$ & $\mathrm{H}$ & $\mathrm{H}$ & 84 & 69 \\
$\mathrm{NHCH}_{3}$ & $\mathrm{H}$ & $\mathrm{NO}_{2}$ & 52 & 87 \\
$\mathrm{NHCH}_{3}$ & $\mathrm{H}$ & $\mathrm{Cl}$ & 35 & 75 \\
$\mathrm{NHCH}_{3}$ & $\mathrm{H}$ & $\mathrm{CH}$ & 40 & 61 \\
$\mathrm{NHCH}_{3}$ & $\mathrm{CH} O$ & $\mathrm{H}$ & 72 & 86 \\
\hline $\mathrm{NH}_{3}$ & $\mathrm{CH}$ & 50 & \\
\hline
\end{tabular}

$\mathrm{N}$ contents by EA: $1.23 \mathrm{mmol} / \mathrm{g}$ for catalyst $\mathrm{NH}_{2}$ and $1.95 \mathrm{mmol} / \mathrm{g}$ for catalyst $\mathrm{NHCH}_{3}$ 
The substituents in the aromatic rings of the benzaldehyde greatly influenced the conversion and the selectivity of flavanones, while the substituents at the meta position of acetophenone affected the conversion less significantly (Table 4). Over a base catalyst, the reaction mechanism generally accepted involves the formation of the anion of acetophenone through the deprotonation of the methyl group, followed by its attack to the carbonyl group on benzaldehyde. If the reaction condition and the substituents present in the aromatic rings are suitable, the chalcone products can cyclize to form the corresponding flavanone isomers [29-31]. According to these pathways, the aldehydes bearing the electron-withdrawing groups in the aromatic ring should be more reactive than those with electron-donating groups. However, the opposite was observed in our system using amino-functionalized silica as the catalysts. It suggests that the reaction mechanism could be different from that over other base catalysts. The previous studies on the adsorption of benzaldehyde on the aminopropyl xerogels by Sartori et al. [35] showed that the $\mathrm{C}=\mathrm{N}$ imine species were formed as the main component and on the basis of imine formation a reaction mechanism for the nitroaldol condensation was proposed. To explain the present reaction results, the imine species were proposed to be one of the intermediates. The modified reaction mechanism is shown in Scheme 2. Over the aminopropylated silica catalysts, the benzaldehyde molecules and the amino groups would form the $\mathrm{C}=\mathrm{N}$ imine species, which was then attacked by the anion of acetophenone to produce the corresponding adduct. The first step of the imine

Scheme 2 Proposed mechanisms over the aminopropylated silica for Claisen-Schmidt condensation formation is the attack by the nucleophilic amine on the carbonyl. A rapid proton transfer results in an unstable intermediate called a carbinolamine. A carbinolamine then reacts to form imine by the loss of water. In the homogeneous system of imine formation, it was reported that under slightly acidic conditions, formation of the carbinolamine intermediate is slow, while under neutral or basic conditions, dehydration of the carbinolamine becomes the slow step [36]. An electron-withdrawing group on benzaldehyde would favor the formation of carbinolamine intermediate but hinder the dehydration process and imine formation, resulting in a decrease of the conversion. However, the electron-withdrawing group on benzaldehyde may facilitate the subsequent chalcone isomerization and increase flavanone selectivity. Table 4 also compares the catalytic performance of SBA-15 functionalized with methylaminopropyl groups to that with aminopropyl groups. Although the former has higher amino loading, the conversions of benzaldehyde were all significantly lower than those over aminopropyl-SBA-15. That seems due to the steric hindrance of the secondary amine sites from the imine formation. As to the diamine-functionalized SBA15 , very low catalytic activities were observed in the Claisen-Schmidt condensation. According to these results, the imine formation should be the key step in determining the conversion. For acetophenone with substituents at the meta position, the influence on the conversion was less significant, while the selectivities of flavanone were higher. The selectivity is likely controlled by the thermodynamic distribution between products $C$ and $D$.
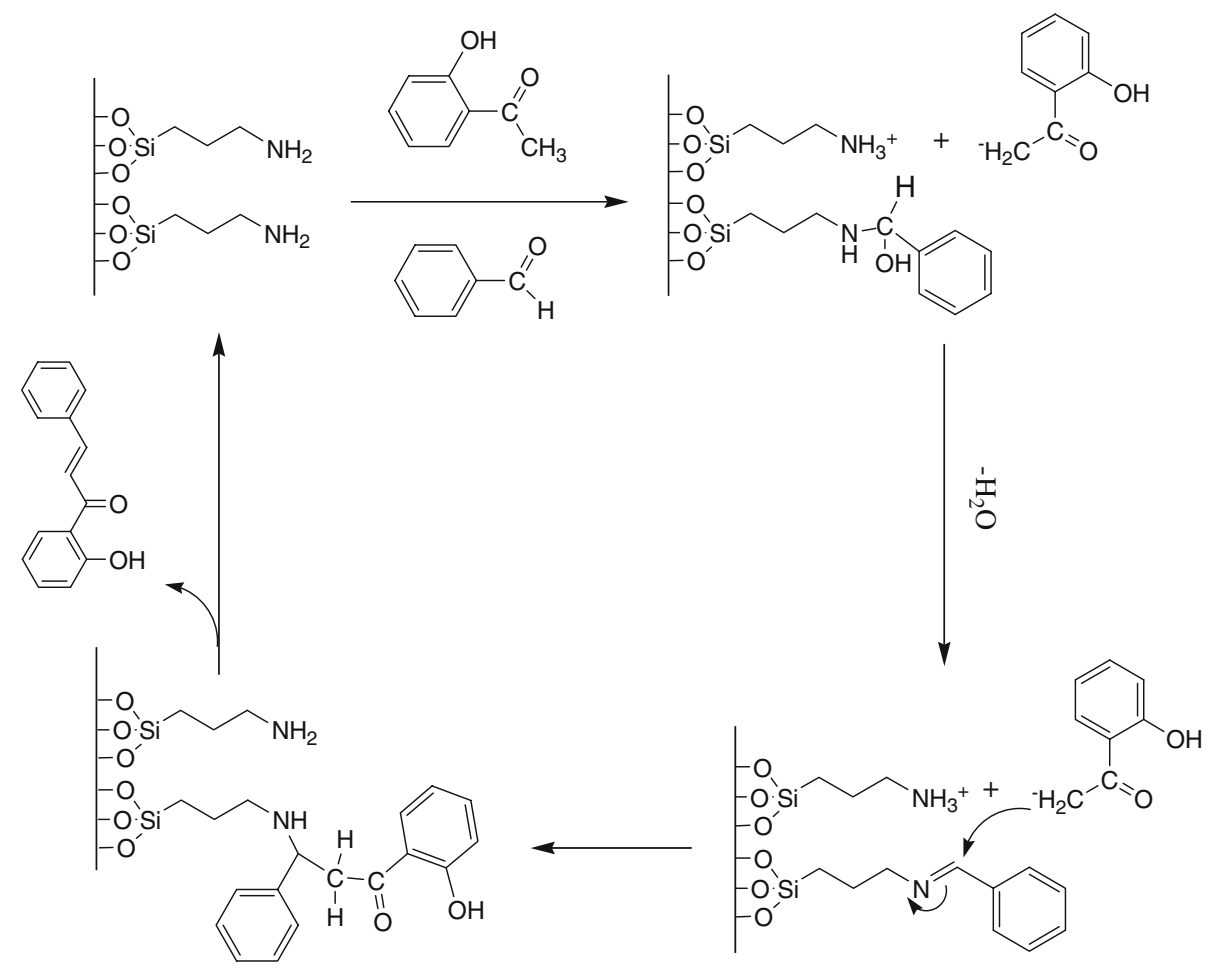


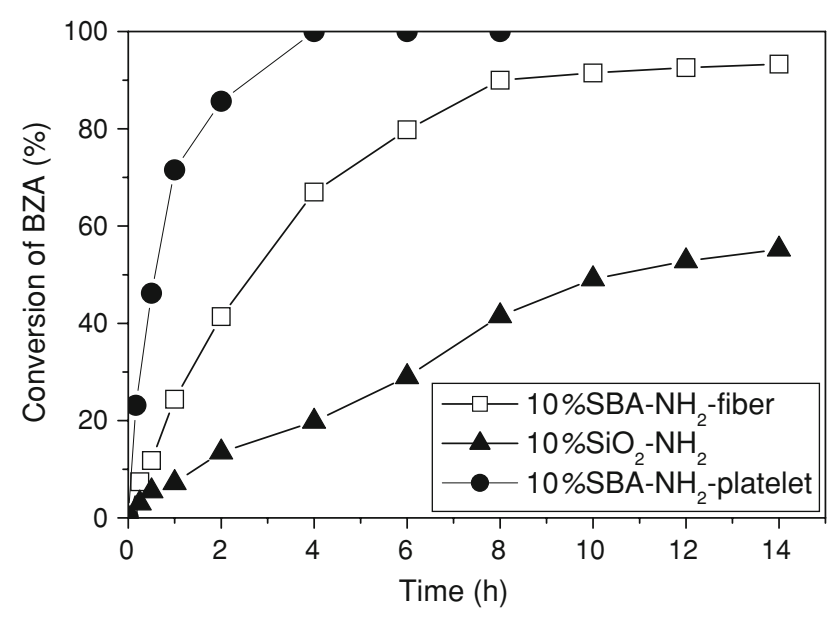

Fig. 3 Benzaldehyde (BZA) conversion in flavanone synthesis at $140{ }^{\circ} \mathrm{C}$ as a function of reaction time over aminopropyl-functionalized SBA-15 of fiber $(\square)$ and platelet $(\bullet)$ morphologies as well as that over functionalized silica gel $(\mathbf{\Delta})$

\subsection{Effect of Catalyst Morphology}

Recently, a facile synthesis route was developed in our laboratory to prepare SBA-15 silica of platelet shape and very short mesochannels $(150-350 \mathrm{~nm})$ by introducing a small amount of $\mathrm{Zr}(\mathrm{IV})$ ions in the synthesis solution [37]. The synthesis route can be easily extended to prepare SBA-15 materials with various organic functional groups and varied channel lengths in one pot. Figure 3 shows that aminopropyl-functionalized SBA-15 with narrow distributed mesopores gave faster rate and much higher conversions in the Claisen-Schmidt condensation than that over functionalized silica gel. This result demonstrates again the advantage of ordered large mesopores of SBA-15 in the proceeding of the liquid phase catalytic reactions. Moreover, the SBA-15 with platelet morphology and short mesochannels could have the reaction rate further increased, in comparison to the conventional SBA-15 of rod or fiber shapes. The platelet SBA-15 is superior to the conventional SBA-15 in facilitating molecular diffusion and less possibility of pore blockage when used in the sorption or reactions of bulky molecules.

Acknowledgements This work was supported by National Science Council and the Ministry of Education, Taiwan.

\section{References}

1. Kresge CT, Leonowicz ME, Roth WJ, Vartuli JC, Beck JS (1992) Nature 359:710

2. Beck JS, Vartuli JC, Roth WJ, Leonowicz ME, Kresge CT, Schmitt KD, Chu CTW, Olson DH, Sheppard EW, McCullen SB,
Higgins JB, Schlenker JL (1992) Journal of the American Chemical Society 114:10834

3. Das D, Lee JF, Cheng S (2004) J Catal 223:152

4. Thomas JM, Raja R (2004) J Organometal Chem 689:4110

5. Yuliarto B, Zhou HS, Yamada T, Honma I, Katsumura Y, Ichihara M (2004) Analytical Chemistry 76:6719

6. Yang PD, Deng T, Zhao DY, Feng PY, Pine D, Chmelka BF, Whitesides GM, Stucky GD (1998) Science 282:2244

7. Lin VSY, Lai CY, Huang JG, Song SA, Xu S (2001) Journal of the American Chemical Society 123:11510

8. Huh S, Chen HT, Wiench JW, Pruski M, Lin VSY (2004) Journal of the American Chemical Society 126:1010

9. Margollese D, Melero JA, Christianesn SC, Chmelka BF, Stucky GD (2000) Chem Mater 12:2448

10. Wang Y, Zibrowius B, Yang C, Spliethoff B, Schüth F (2004) Chem Commun 46

11. Shah J, Kim SS, Pinnavaia TJ (2004) Chem Commun 572

12. Burleigh MC, Markowitz MA, Spector MS, Gaber BP (2001) Chem Mater 13:4760

13. Goto Y, Inagaki S (2002) Chem Commun 2410

14. Yokoi T, Yoshitake H, Tatsumi TJ (2004) Mater Chem 14:951

15. Beaudet L, Hossain KZ, Mercier L (2003) Chem Mater 15:327

16. Walcarius A, Delacote C (2003) Chem Mater 15:4181

17. Macquarrie DJ, Jackson DB (1997) Chem Commun 1781

18. Utting KA, Macquarrie DJ (2000) New J Chem 24:591

19. Brunel D, Fajula F, Nagy JB, Deroide B, Verhoef MJ, Veum L, Peters JA, Van Bekkum H (2001) Appl Catal A: Gen 213:73

20. Chong ASM, Zhao XS (2003) J Phys Chem B 107:12650

21. Yiu HHP, Wright PA, Botting NP (2001) Journal of Molecular Catalysis. B, Enzymatic 15:81

22. Wang X, Lin KSK, Chan JCC, Cheng S (2004) Chem Commun 2762

23. Wang X, Lin KSK, Chan JCC, Cheng S (2005) J Phys Chem B 109:1763

24. Wang X, Tseng Y-H, Chan JCC, Cheng S (2005) Micropor Mesopor Mat 85:241

25. Wang X, Chan JCC, Tseng YH, Cheng S (2006) Micropor Mesopor Mat 95:57

26. Guo W, Park JY, Oh MO, Jeong HW, Cho WJ, Kim I, Ha CS (2003) Chem Mater 15:2295

27. Zhao XS, Lu GQ, Whittaker AK, Millar GJ, Zhu HY (1997) J Phys Chem B 101:6525

28. Wang X, Cheng S (2006) Catalysis Communications 7:689

29. Dahr DN (1981) The chemistry of chalcones and related compounds. Wiley, New York

30. Harbone JB, Mabry TJ (1982) The flavonoids: advances in research. Chapman \&Hall, New York

31. Sheldon RA, Downing RS (1999) Appl. Catal. A Gen. 189:163

32. Besson M, Bonnet MC, Gallezot P, Tkatchenko I, Tuel A (1999) Catal. Today 51:547

33. Drexler MT, Amiridis MD (2003) J. Catal. 214:136

34. Varma RS, Kabalka GW, Evans LT, Pagni RM (1985) Synthetic Communications 15:279

35. Sartori G, Bigi F, Maggi R, Sartorio R, Macquarrie DJ, Lenarda M, Storaro L, Coluccia S, Martra G (2004) J. Catal. 222:410

36. Moscovi R, Ferraz JP, Neves EA, Tognoli JO, El Seoud MI, do Amaral LJ (1976) Org Chem 41:4093

37. Chen S-Y, Tang C-Y, Chuang W-T, Lee J-J, Tsai Y-L, Chan JCC, Lin C-Y, Liu Y-C, Cheng S (2008) Chem. Mater. 20:3906 